\title{
Biosynthesis of triacylglycerol in the filamentous fungus Mucor circinelloides
}

\author{
Frances M. Jackson, ${ }^{1}$ Louise Michaelson, ${ }^{1}$ Thomas C. M. Fraser, ${ }^{1}$ \\ A. Keith Stobart' and Gareth Griffiths ${ }^{2}$
}

Author for correspondence: Gareth Griffiths. Tel: +44 1789 470382. Fax : +44 1789470552.

e-mail: Gareth.Griffiths@HRI.ac.uk

1 School of Biological Sciences, University of Bristol, Woodland Road, Bristol BS8 1UG, UK

2 Department of Plant Genetics and Biotechnology, Horticulture Research International, Wellesbourne, Warwickshire CV35 9EF, UK

\begin{abstract}
Lipid metabolism was studied in 2-d-old liquid cultures of Mucor circinelloides grown at $25{ }^{\circ} \mathrm{C}$. Under these conditions, oil accumulated to $0.5 \mathrm{~g} \mathrm{I}^{-1}$ with a $\gamma$-linolenic acid content ( $\gamma$ 18:3) of $60 \mathrm{mg} \mathrm{l}^{-1}$. The major labelled lipids in cultures incubated with $\left[{ }^{14} \mathrm{C}\right]$ acetate were triacylglycerol (TAG), phosphatidylcholine (PC) and phosphatidylethanolamine (PE). The proportion of label declined in the phospholipids and increased in TAG with time. $\left[{ }^{14} \mathrm{C}\right] 18: 1$ and $\left[{ }^{14} \mathrm{C}\right] 18: 2$ rapidly appeared in $\mathrm{PC}$ and $\mathrm{PE}$ and later accumulated in $\left[{ }^{14} \mathrm{C}\right]$ \%18:3. TAG-synthesizing capacity was greatest in the microsomal membrane fraction, which accumulated high levels of phosphatidic acid in the presence of glycerol 3-phosphate and acyl-CoA substrates at pH 7-0. Further metabolism of phosphatidic acid to diacylglycerol and TAG was achieved by increasing the pH to 8.0. Lysophosphatidic acid: acyl-CoA acyltransferase (LPAAT) activity was particularly high and may have accounted for the rapid accumulation of phosphatidic acid in the membranes. The glycerol-3-phosphate :acyl-CoA acyltransferase (GPAAT) and LPAAT were non-specific for a range of saturated and unsaturated species of acyl-COA although the GPAAT showed a marked selectivity for palmitoyl-COA and the LPAAT for oleoyl- and linoleoyl-COA. $\gamma$-Linolenic acid was detected at all three positions of sn-TAG and was particularly enriched at the $s n-3$ position. The preparation of active in vitro systems (microsomal membranes) capable of the complete biosynthetic pathway for TAG assembly may be valuable in understanding the assembly of oils in future transgenic applications.
\end{abstract}

Keywords: Mucor circinelloides, gamma-linolenic acid, microsomes, triacylglycerol biosynthesis

\section{INTRODUCTION}

The biosynthesis of polyunsaturated fatty acids in plants (Stymne \& Stobart, 1987; Harwood, 1988; Slabas et al., 1993) and animals (Brenner, 1982; Sprecher et al., 1995) and their assembly to produce storage fats and oils have been extensively studied. By comparison, and with the exception of oleaginous yeasts (Johnson et al., 1994; Sancholle \& Lösel, 1995; Meesters \& Eggink, 1996), few detailed biochemical studies on lipid synthesis in fungi have been undertaken. Of particular commercial interest is the production of so-called 'speciality oils' by microbes as alternative sources to those derived from

Abbreviations: $\mathrm{PA}$, phosphatidic acid; $\mathrm{PC}$, phosphatidylcholine; $\mathrm{PE}$ phosphatidylethanolamine; PI, phosphatidylinositol; DAG, diacylglycerol; TAG, triacylglycerol; GPAAT, glycerol-3-phosphate:acyl-CoA acyltransferase; LPAAT, lysophosphatidic acid:acyl-CoA acyltransferase. oilseeds (Ratledge, 1993). In particular, there is considerable interest in the biosynthesis of $\gamma$-linolenic acid $(\mathrm{C} 18: 3, \Delta 6,9,12 ; \gamma 18: 3)$. This fatty acid is an important precursor in the production of prostaglandins in the body (Horrobin, 1990; Zurier, 1993), and supplementing dietary intakes with this component (usually oil extracted from evening primrose seeds) may have significant health benefits for a range of disorders (Horrobin, 1990, 1994). A number of fungi including Mucor and Mortierella species have also been identified which contain high levels of $\gamma 18: 3$ (Burnanova et al., 1990; Nakahara et al., 1992; Certik et al., 1993) and have been grown on an industrial scale (Suzuki, 1988).

Triacylglycerols (TAGs) are synthesized by the two-step acylation of $s n$-glycerol 3-phosphate to produce phosphatidic acid (PA), catalysed by the enzymes glycerol-3phosphate:acyl-CoA acyltransferase (GPAAT) and 
lysophosphatidic acid:acyl-CoA acyltransferase (LPAAT) (Stymne \& Stobart, 1987). These enzymes usually display selectivity for the species of acyl-CoA used and govern the non-random distribution of fatty acids in $s n$ TAG (Griffiths et al., 1985). The PA formed is subsequently dephosphorylated to diacylglycerol (DAG) by phosphatidate phosphohydrolase. The DAG then serves as a precursor for TAG and this third acylation step is catalysed by diacylglycerol:acyl-CoA acyltransferase. In oilseeds, phosphatidylcholine (PC) has also been identified as an intermediate in oil biosynthesis and plays a central role in the production of polyunsaturated fatty acids by serving as a substrate for the $\Delta 12$ and $\Delta 6$ desaturases (Stobart \& Stymne, 1985; Griffiths et al., 1988a). Recently we have also shown that PC is a substrate for these desaturases in Mucor circinelloides (Jackson et al., 1998). In oilseeds, all of the enzymes required to catalyse TAG formation and to synthesize polyunsaturated fatty acids reside in the microsomal membrane fraction, which is derived largely from the endoplasmic reticulum (Stobart \& Stymne, 1990). The ability of fungal microsomal membranes to synthesize polyunsaturated TAGs is less certain. Holdsworth \& Ratledge (1991), using the oleaginous yeast Candida curvata, reported that PA formation was mainly in the mitochondrion and that only in reconstituted assays containing spheroplasts, mitochondria, microsomal and lipid bodies and supernatant fractions could TAGsynthesizing activity be obtained. As a prerequisite to biotechnological development of fungi with desired oil quality traits it is important to obtain active in vitro preparations in which to study the assembly of TAGs in transgenics. In this paper we describe the preparation of microsomal membranes capable of TAG assembly from $M$. circinelloides, and report on the biochemical properties of the acylating enzymes.

\section{METHODS}

Chemicals. Reagent-grade chemicals were used. Fine chemicals were purchased from Sigma and solvents from Fisons. [1$\left.{ }^{14} \mathrm{C}\right]$ Acetate and $1{ }^{14} \mathrm{C}$-labelled fatty acids were obtained from Amersham. CoA esters of the fatty acids were synthesized from the mixed anhydrides as described by Stobart \& Stymne (1990). They had a purity greater than $96 \%$ as determined by TLC and GLC, and had the following specific activities: [1${ }^{14}$ C]palmitoyl-CoA, 5328 d.p.m. nmol ${ }^{-1}$; stearoyl-CoA, 5910 d.p.m. nmol ${ }^{-1}$; oleoyl-CoA, 5842 d.p.m. nmol $^{-1}$; linoleoylCoA 5510, d.p.m. nmol ${ }^{-1}$.

Fungal growth. Mucor circinelloides (provided by Professor R. A. Herbert, Dundee University, UK) was transferred from slopes on to malt agar plates and incubated at $25^{\circ} \mathrm{C}$ until confluent. Sterile broth ( $250 \mathrm{ml}$ in $500 \mathrm{ml}$ Erhlenmeyer flasks) of composition $95 \cdot 75$ g glucose $^{-1}, 7 \cdot 02 \mathrm{~g}\left(\mathrm{NH}_{4}\right)_{2} \mathrm{SO}_{4} l^{-1}, 6.00 \mathrm{~g}$ $\mathrm{KH}_{2} \mathrm{PO}_{4} \mathrm{l}^{-1} ; 1 \cdot 20 \mathrm{~g} \mathrm{MgSO}_{4} \cdot 7 \mathrm{H}_{2} \mathrm{Ol}^{-1}, 1 \cdot 00 \mathrm{~g}$ yeast extract $\mathrm{l}^{-1}$ was inoculated with a $5 \times 5 \mathrm{~mm}$ square of $M$. circinelloides mycelium and transferred to a Gallenkamp orbital shaker, and growth was allowed to proceed at $25^{\circ} \mathrm{C}$ (see Results) and 200 r.p.m. Growth was measured by wet and dry weight measurement and reached a maximum by 7-8 $\mathrm{d}$ after inoculation. Microsomal membranes were prepared from cultures after $2 \mathrm{~d}$ growth.

Microsomal membrane preparation. Cultures were harvested by filtration and kept on ice. All further procedures were carried out at $4{ }^{\circ} \mathrm{C}$. Cells were ruptured according to the method of Murcott et al. (1991). Cells were suspended in $0.1 \mathrm{M}$ potassium phosphate buffer, $\mathrm{pH} 7 \cdot 2$, containing $0.33 \mathrm{M}$ sucrose, $0 \cdot 1 \%(\mathrm{w} / \mathrm{v})$ bovine serum albumin (fatty acid free), 1000 units catalase $\mathrm{ml}^{-1}$ and $1 \mathrm{mM}$ Pefabloc. Glass beads $(0.4 \mathrm{~mm}$ diameter $)$ were added and the resultant slurry was stirred overhead at 2000 r.p.m. using a glass paddle mounted in a Black and Decker BD154R variable-speed power drill. The homogenate was filtered through a glass sinter, diluted with fresh grinding buffer and centrifuged $(20000 \mathrm{~g}, 15 \mathrm{~min})$. The supernatant was filtered through a layer of Miracloth and centrifuged $(100000 \mathrm{~g}, 60 \mathrm{~min})$. The resultant pellet (microsomal membranes) was washed with cold $0 \cdot 1 \mathrm{M}$ potassium phosphate buffer, $\mathrm{pH} 7 \cdot 2$, and resuspended in a PotterElvehjelm homogenizer using a small volume of the same buffer containing glycerol $(20 \%, \mathrm{v} / \mathrm{v})$. Microsomes were either used immediately or frozen rapidly at $-80^{\circ} \mathrm{C}$, at which temperature they could be stored until required without significant loss of activity.

Oil bodies were obtained from the first $20000 \mathrm{~g} \times 15 \mathrm{~min}$ centrifugation step and the fat pad was washed in fresh homogenization buffer and recentrifuged at $20000 \mathrm{~g}$ for $15 \mathrm{~min}$. Freshly prepared oil bodies were used in the experiments reported.

Analytical procedures. Lipids were extracted from whole cells by a modification of the method described by Bligh \& Dyer (1959). The fungal cells were acidified with $0 \cdot 15 \mathrm{M}$ acetic acid $(1 \mathrm{ml})$ followed by the addition of chloroform/methanol $1: 2$, $\mathrm{v} / \mathrm{v} ; 7.5 \mathrm{ml})$, distilled water $(2.25 \mathrm{ml})$ and chloroform $(2 \cdot 25 \mathrm{ml})$. Phase separation was achieved by low-speed centrifugation and the lower chloroform phase containing the lipids was removed and evaporated under $\mathrm{N}_{2}$. Samples were resuspended in a small volume of chloroform and stored at $-20^{\circ} \mathrm{C}$ until required. Membrane lipid extracts were made using chloroform/methanol/acetic acid $(50: 50: 1$, by vol.) and the lower chloroform phase was again recovered by lowspeed centrifugation. Lipids were purified by TLC on precoated silica gel plates (Merck, silica gel 60). Neutral lipids were separated using hexane/diethyl ether/acetic acid (70: $30: 1$, by vol.) and polar lipids using chloroform/methanol/ acetic acid/water (170:30:20:7, by vol.) (Stobart \& Stymne, 1990).

Lipids were located by lightly staining with iodine vapour and then removed from the plates for radioassay or transmethylation for the analysis of fatty acids. The fatty acid methyl esters were prepared in $2.5 \%(\mathrm{v} / \mathrm{v})$ sulphuric acid in anhydrous methanol ( $2 \mathrm{ml}$ ) (Griffiths et al., 1997) and quantified by GLC using heptadecanoic acid as internal standard on a GP $10 \%$ sp-2330 100/120 Chromosorb W AW (Supelco) column. Radiolabelled monoenoic, dienoic and trienoic fatty acid methyl esters were separated by argentationTLC (Stobart \& Stymne, 1990).

Positional analysis of fatty acids in PA and TAG. Phosphatidic acid was purified by TLC and eluted from the gel in methanol/chloroform (2:1, by vol.). The eluate was evaporated to dryness under $\mathrm{N}_{2}$ and the residue redissolved in diethyl ether $(1 \mathrm{ml})$. The lipid sample in diethyl ether was sonicated with $0 \cdot 1 \mathrm{M}$ sodium borate buffer, $\mathrm{pH} 8 \cdot 9$, and phospholipase $\mathrm{A}_{2}$ (30 units) was added. After incubation, with vigorous mixing, at $25^{\circ} \mathrm{C}$ for $80 \mathrm{~min}$ the fatty acids and lysophosphatidic acid were extracted in water-saturated butanol (Griffiths et al., 1985).

Stereochemical analyses of TAG were performed essentially as described by Christie (1982). TAGs purified by TLC were hydrolysed with Grignard reagent (ethyl magnesium bromide) 
and the $s n-1,2$ diacylglycerols recovered were chemically converted to PCs. These were digested with phospholipase $\mathrm{A}_{2}$; the fatty acids liberated represent those at the $s n-2$ position of the original TAG while those in lysophosphatidylcholine represent fatty acids at the $s n-1$ position. The fatty acids at the $s n-3$ position were calculated by subtraction using [position $s n-3]=3 \times[$ TAG] $-[$ position $s n-1]-[$ position $s n-2]$.

Enzyme assays. The specificity of GPAAT and LPAAT was determined using single-substrate acyl-CoA species as follows. Microsomes (equivalent to $0.5 \mathrm{mg}$ protein) were incubated with $\left[{ }^{14} \mathrm{C}\right]$ palmitoyl-CoA, $\left[{ }^{14} \mathrm{C}\right]$ stearoyl-CoA, $\left[{ }^{14} \mathrm{C}\right]$ oleoyl$\mathrm{CoA}$ or $\left[{ }^{14} \mathrm{C}\right]$ linoleoyl-CoA in the presence of glycerol 3phosphate $(400 \mathrm{nmol})$ in $0.1 \mathrm{M}$ potassium phosphate buffer, $\mathrm{pH} 7 \cdot 2$, for $30 \mathrm{~min}$ at $25^{\circ} \mathrm{C}$. In studies on the acyl-CoA selectivity of these enzymes a mixture of $50 \mathrm{nmol}$ of each of the acyl-CoA substrates was used.

LPAAT activity was also measured in a continuous assay using DTNB [5, $5^{\prime}$-dithiobis (2-nitrobenzoic acid) $]$ and following the change in $A_{409}$ at $25^{\circ} \mathrm{C}$. The assay, modified from the method used by Stymne \& Stobart (1984) for lysophosphatidylcholine:acyl-CoA acyltransferase, routinely contained DTNB $(50 \mathrm{nmol})$, oleoyl-CoA $(20 \mathrm{nmol})$ and potassium phosphate buffer $(50 \mathrm{mM})$, pH 7.2. Palmitoyl lysophosphatidic acid $(30 \mathrm{nmol})$ was added to the sample cuvette and reactions were initiated by addition of microsomes (final vol. $1 \mathrm{ml}$ ). Other acyl-CoA donors were also examined. Initial rates were used to calculate activity using a molar absorption coefficient of $13.6 \mathrm{mM}^{-1} \mathrm{~cm}^{-1}$.

Protein determinations. The bicinchoninic acid protein assay (Pierce and Warriner) standard protocol was used, with bovine serum albumin as a standard.

\section{RESULTS}

\section{Incorporation of $\left[{ }^{14} \mathrm{C}\right]$ acetate into lipids}

Acetate serves as a good substrate for the de novo biosynthesis of fatty acids and is readily taken up by tissues. The principal products of fatty acid synthesis are $16: 0$ and $18: 1$, so incorporation of acetate into these fatty acids would provide information on how these products were further used in desaturation and oil assembly. Two-day-old liquid cultures of M. circinelloides were incubated with $\left[1-{ }^{14} \mathrm{C}\right]$ acetate in timecourse studies (up to $6 \mathrm{~h}$ ), and the lipids were extracted, purified and the distribution of label in the various acyl constituents of the complex lipids determined.

The major labelled lipids from $\left[{ }^{14} \mathrm{C}\right]$ acetate were TAG, $\mathrm{PC}$ and to a lesser extent PE (data not given). The proportion of label in the phospholipids declined from initial values and there was a concomitant increase in radioactivity in TAG (data not given). The ${ }^{14} \mathrm{C}$-labelled fatty acid profiles of PC, PE and TAG over the time course are shown in Fig. $1 .\left[{ }^{14} \mathrm{C}\right] 18: 1$ and $\left[{ }^{14} \mathrm{C}\right] 18: 2$ rapidly appeared in $\mathrm{PC}$ and then declined with time; radioactivity accumulated in $\left[{ }^{14} \mathrm{C}\right] \gamma 18: 3$ throughout the incubation. A similar trend was observed for PE, although a lower relative labelling of $18: 2$ and $\gamma 18: 3$ occurred. Negligible levels of radioactivity were detected in phosphatidylinositol (PI) (data not shown). In TAG, $\left[{ }^{14} \mathrm{C}\right] 18: 1$ was the most abundant fatty acid throughout the time course together with saturated fatty acids $(16: 0$ plus 18:0). Labelling of the polyunsaturated fatty acids, $18: 2$ and $\gamma 18: 3$, on the other hand, was low (approx.
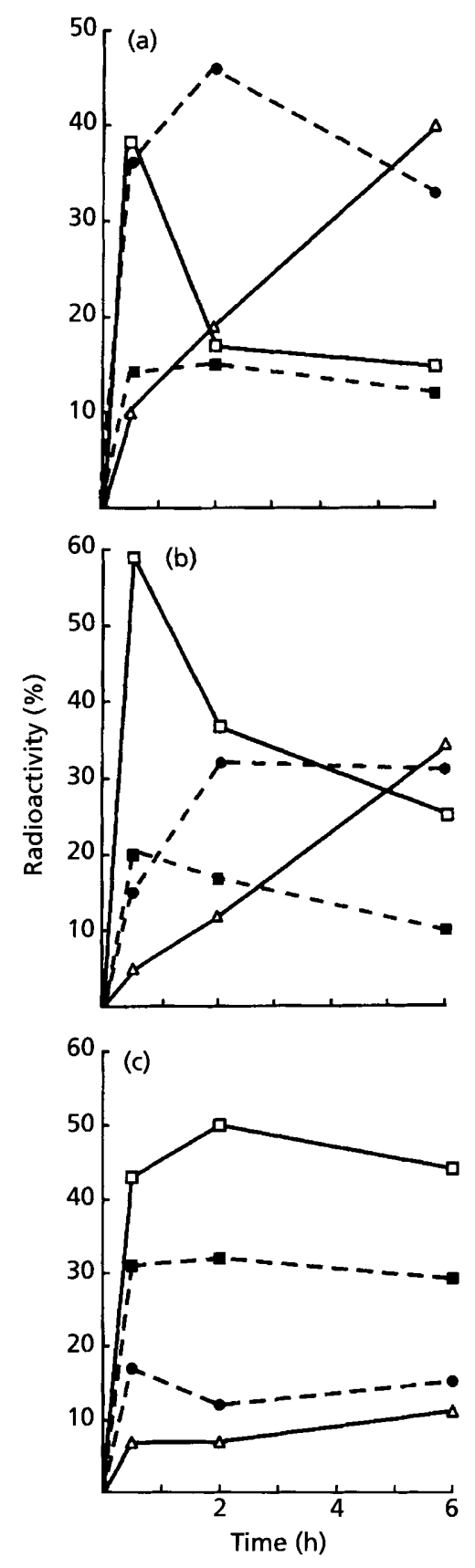

Fig. 1. Incorporation of radioactivity from $\left[{ }^{14} \mathrm{C}\right]$ acetate into fatty acids of (a) PC, (b), PE and (c) TAG. Fungal cells (2-d-old cultures) in $10 \mathrm{ml}$ medium (equivalent to $0.1 \mathrm{~g}$ wet $\mathrm{wt}$ ) were incubated with $\left[1-{ }^{14} \mathrm{C}\right]$ acetate $\left(18.5 \times 10^{4} \mathrm{~Bq}\right.$, specific activity $2.11 \times 10^{3} \mathrm{GBq} \mathrm{mol}^{-1}$ ) for the times indicated and the lipids were extracted, purified by TLC and transmethylated. The fatty acid methyl esters were purified by argentation-TLC and radioactivity in the saturates $(16: 0$ plus $18: 0 ; \square)$, monoenoates $(18: 1 ; \square)$, dienoates $(18: 2 ; \bullet)$ and trienoates $(\gamma 18: 3 ; \triangle)$ was determined by liquid scintillation. Tissues contained $30 \pm 5 \mathrm{MBq}$ $(\mathrm{g} \text { wet } \mathrm{wt})^{-1}$.

$25 \%$ after $6 \mathrm{~h}$ ). Further characterization of oil assembly was undertaken following subcellular fractionation of the cells by measuring the in vitro activity of the socalled Kennedy pathway enzymes. 
Table 1. Incorporation of $s n-\left[1-{ }^{14} \mathrm{C}\right]$ glycerol 3-phosphate into lipids by microsomal membranes

Microsomal membranes (equivalent to $0.5 \mathrm{mg}$ protein) were incubated with $\left[1-{ }^{14} \mathrm{C}\right]$ glycerol 3 -phosphate $(500 \mathrm{nmol}$; specific activity 2559 d.p.m. nmol $\left.{ }^{-1}\right)$ and oleoyl-CoA (100 nmol) in phosphate buffer, $\mathrm{pH} 8 \cdot 0(0 \cdot 1 \mathrm{M}, 1 \mathrm{ml}$ final volume $)$; the lipids were extracted at the times indicated and the radioactive distribution determined. Results are representative of an experiment repeated twice.

\begin{tabular}{|c|c|c|c|c|c|c|}
\hline \multirow{2}{*}{$\begin{array}{l}\text { Time } \\
\text { (min) }\end{array}$} & \multicolumn{5}{|c|}{ Radioactivity (\%) } & \multirow{2}{*}{$\begin{array}{c}\text { Total } \\
{[\text { nmol }(\mathbf{m g}} \\
\left.\text { protein })^{-1}\right]\end{array}$} \\
\hline & PA & PC & PE & DAG & TAG & \\
\hline 10 & 72 & 18 & 2 & 5 & 4 & 110 \\
\hline 20 & 61 & 23 & 2 & 6 & 8 & 130 \\
\hline 60 & 50 & 25 & 2 & 12 & 11 & 144 \\
\hline 100 & 44 & 26 & 2 & 14 & 14 & 140 \\
\hline
\end{tabular}

\section{Incorporation of $\left[{ }^{14} \mathrm{C}\right]$ glycerol 3-phosphate into subcellular fractions}

Oil-body and microsomal membrane fractions were assayed for TAG biosynthetic activity using $\left[{ }^{14} \mathrm{C}\right]-$ glycerol 3-phosphate and oleoyl-CoA as substrates. Most of the activity $(90 \%)$ was recovered in the microsomes (equivalent to $2 \cdot 3 \mu \mathrm{mol}\left[{ }^{14} \mathrm{C}\right] \mathrm{glycerol} 3$ phosphate incorporated into total lipids from $12 \mathrm{~g}$ wet weight of mycelia) and the remaining $10 \%$ was detected in the oil-bodies. PA was the predominantly labelled lipid in both preparations $(78 \pm 1 \%$ ), with only small amounts (approx. $5 \%$ ) in each of PC, PE, DAG and TAG. The results indicated that acylation of glycerol 3phosphate to PA had occurred and that further metabolism of PA to DAG by the phosphohydrolase enzyme was slow, with concomitantly little increase in label in TAG. We have shown that the activity of phosphohydrolase in oilseed microsomes can be manipulated by the availability of $\mathrm{Mg}^{2+}$ (Griffiths et al., 1985). Addition of $\mathrm{Mg}^{2+}(10 \mathrm{mM})$ and EDTA $(10 \mathrm{mM})$ alone or in combination failed to stimulate the further metabolism of PA to DAG and TAG (data not shown). However, increasing the $\mathrm{pH}$ of the reaction mixture from $7 \cdot 0$ to $8 \cdot 0$ resulted in a significant increase in label in PC (almost fourfold), with radioactivity slowly accumulating in both DAG and TAG (Table 1).

\section{Spectrophotometric determination of LPAAT activity}

The accumulation of $\left[{ }^{14} \mathrm{C}\right]$ glycerol in PA may result from a low phosphohydrolase activity as outlined above. Alternatively, such a result could arise from a relatively rapid rate of acyl transfer to glycerol 3-phosphate compared with the rate of PA hydrolysis. To determine if $M$. circinelloides had particularly high rates of acylation, the activity of LPAAT was determined spectrophotometrically using sunflower and guinea-pig liver microsomes for comparison. Two $\mathrm{pH}$ conditions were examined, $\mathrm{pH} 7 \cdot 0$ and $8 \cdot 0$; the activity of the $M$. circinelloides LPAAT was substantially higher than
Table 2. Incorporation of $\left[{ }^{14} \mathrm{C}\right] \mathrm{acyl}-\mathrm{CoAs}$ into microsomal phosphatidate

Microsomes $(0.5 \mathrm{mg}$ protein) were incubated with $200 \mathrm{nmol}$ of either $\left[{ }^{14} \mathrm{C}\right] 16: 0-\mathrm{CoA},\left[{ }^{14} \mathrm{C}\right] 18: 0-\mathrm{CoA},\left[{ }^{14} \mathrm{C}\right] 18: 1-\mathrm{CoA}$ or $\left[{ }^{14} \mathrm{C}\right] 18: 2-\mathrm{CoA}$ (single substrate) or with $50 \mathrm{nmol}$ of each substrate (mixed substrate) in the presence of glycerol 3phosphate $(400 \mathrm{nmol})$ in phosphate buffer, $\mathrm{pH} 7 \cdot 2$, for $30 \mathrm{~min}$. Lipids were extracted and the positional distribution of radioactivity in phosphatidate was determined. Similar results were obtained on two other occasions (SE typically $<5 \%$ of the mean for each value). ND, Not detected.

\begin{tabular}{|c|c|c|}
\hline \multirow[t]{2}{*}{${ }^{14} \mathrm{C}$-labelled fatty acid } & \multicolumn{2}{|c|}{$\begin{array}{l}\text { Positional distribution } \\
(\mathbf{n m o l})^{*}\end{array}$} \\
\hline & $s n-1$ & $s n-2$ \\
\hline \multicolumn{3}{|l|}{ Single substrate } \\
\hline $16: 0$ & $26 \cdot 2(54)$ & $22 \cdot 3(46)$ \\
\hline $18: 0$ & $5 \cdot 6(68)$ & $2.7(32)$ \\
\hline $18: 1$ & $15 \cdot 4(34)$ & $29 \cdot 8(66)$ \\
\hline $18: 2$ & $6 \cdot 4(33)$ & $13 \cdot 1(67)$ \\
\hline \multicolumn{3}{|l|}{ Mixed substrate } \\
\hline $16: 0$ & $7 \cdot 1(87)$ & $1 \cdot 1(13)$ \\
\hline $18: 0$ & ND & ND \\
\hline $18: 1$ & $2 \cdot 1(38)$ & $3 \cdot 3(62)$ \\
\hline $18: 2$ & $2 \cdot 4(31)$ & $5 \cdot 5(69)$ \\
\hline
\end{tabular}

"The numbers in parentheses represent the percentage distribution between the $s n-1$ and $s n-2$ positions.

either of the two other preparations at both $\mathrm{pH}$ values. At $\mathrm{pH} 7 \cdot 0$, activities $\left[\mathrm{nmol} \mathrm{min}^{-1}(\mathrm{mg} \text { protein })^{-1}\right.$ ] were: M. circinelloides 79 , sunflower 11 and guinea-pig liver 33. At $\mathrm{pH} 8 \cdot 0$, activities [nmol $\mathrm{min}^{-1}(\mathrm{mg} \text { protein })^{-1}$ ] were: $M$. circinelloides 120 , sunflower 48 and guinea-pig liver 49.

\section{Utilization of $\left[{ }^{14} \mathrm{C}\right]$ acyl-CoA substrates in the acylation of glycerol 3-phosphate}

The accumulation of radioactivity from $\left[{ }^{14} \mathrm{C}\right]$ glycerol 3phosphate into $\mathrm{PA}$ at $\mathrm{pH} 7$ provided an opportunity for studying the acyl specificity and selectivity of the acyltransferases for different acyl-CoA substrates. The specificity of the acylating enzymes was investigated using single-substrate $\left[{ }^{14} \mathrm{C}\right]$ acyl-CoA in the presence of unlabelled glycerol 3-phosphate. When acyl-CoA substrates are presented to microsomal membranes they can, potentially, enter into an acyl-exchange with acyl groups, predominantly the $\mathrm{C}_{18}$ polyunsaturated fatty acids, at position $s n-2$ of PC (Stymne \& Stobart, 1984; Griffiths et al., 1985). This results in unlabelled fatty acids being made available to the acyl-CoA pool for utilization in the acylation of glycerol 3-phosphate in addition to the exogenously supplied radiolabelled acylCoAs. The results showed that $16: 0$ and $18: 1$ were most effectively incorporated into PA (Table 2). 18:2 was also efficiently utilized whereas $18: 0$, on the other hand, was a relatively poor substrate. Stereospecific analysis (Table 


\section{Table 3. Positional distribution of fatty acids in TAG}

Purified TAG was subjected to random chemical deacylation followed by derivatization of purified $s n-1,2$ DAG to PC. The distribution of fatty acids at the $s n-1$ and $s n-2$ positions was then determined following phospholipase $\mathrm{A}_{2}$ digestion and GLC analysis of the fatty acids, and position $s n-3$ determined by calculation. Comp, relative acyl composition of each position; Dist, relative distribution of each acyl group between the three positions; ND, not detected.

\begin{tabular}{|c|c|c|c|c|c|c|c|c|c|c|}
\hline \multirow[t]{3}{*}{ Position } & \multicolumn{10}{|c|}{ Fatty acid composition/distribution (mol\%) } \\
\hline & \multicolumn{2}{|c|}{$16: 0$} & \multicolumn{2}{|c|}{$18: 0$} & \multicolumn{2}{|c|}{$18: 1$} & \multicolumn{2}{|c|}{$18: 2$} & \multicolumn{2}{|c|}{$\gamma 18: 3$} \\
\hline & Comp & Dist & Comp & Dist & Comp & Dist & Comp & Dist & Comp & Dist \\
\hline$s n-1$ & $61 \cdot 4$ & $51 \cdot 8$ & $7 \cdot 1$ & $52 \cdot 3$ & $21 \cdot 5$ & $23 \cdot 6$ & $3 \cdot 3$ & $7 \cdot 9$ & 6.7 & $17 \cdot 8$ \\
\hline$s n-2$ & $8 \cdot 9$ & $5 \cdot 9$ & $6 \cdot 5$ & $47 \cdot 8$ & $47 \cdot 3$ & $52 \cdot 2$ & $28 \cdot 4$ & $66 \cdot 2$ & $9 \cdot 0$ & $26 \cdot 4$ \\
\hline$s n-3$ & $48 \cdot 2$ & $42 \cdot 5$ & ND & ND & $21 \cdot 2$ & $24 \cdot 2$ & $11 \cdot 2$ & $25 \cdot 8$ & $20 \cdot 6$ & $55 \cdot 8$ \\
\hline Total* & $39 \cdot 0$ & & $4 \cdot 0$ & & $30 \cdot 5$ & & $14 \cdot 3$ & & $12 \cdot 1$ & \\
\hline
\end{tabular}

*Actual composition of the triacylglycerol molecule determined by directly methylating the purified lipid.

2) showed that $16: 0$ was almost evenly distributed between the $s n-1$ and $s n-2$ position whereas $18: 1$ and $18: 2$ were preferentially acylated to the $s n-2$ position. $18: 0$, however, was preferentially located at the $s n-1$ position.

To investigate the acyl selectivity of the acyltransferases, microsomes were incubated with mixed $\left[{ }^{14} \mathrm{C}\right]$ acyl-CoA substrates and glycerol 3-phosphate. Under these conditions 16:0 was extensively used for the acylation of position $s n$-1 of glycerol 3-phosphate whereas both $\left[{ }^{14} \mathrm{C}\right] 18: 1$ and $\left[{ }^{14} \mathrm{C}\right] 18: 2$ were preferentially acylated to the $s n$-2 position and $\left[{ }^{14} \mathrm{C}\right] 18: 0$ was not utilized (Table 2).

\section{Positional analysis of TAG}

Purified TAG was subjected to random chemical deacylation followed by derivitization of purified $s n-1,2$ DAG to PC. The distribution of fatty acids at the $s n-1$ and $s n-2$ positions was then determined following phospholipase $\mathrm{A}_{2}$ digestion and GLC analysis of the fatty acids. The acyl composition of $s n-3$ was determined indirectly by calculation (see Methods). 16:0, a major fatty acid in the fungus, was present largely in positions $s n-1$ and $s n-3$ with only a small proportion located at the $s n-2$ position (Table 3 ). Only low levels of 18:0 were present in TAG (4\% total) and were evenly distributed between positions $s n-1$ and $s n-2$. 18:1 was found to reside in similar amounts in position $s n-1$ and $s n-3$, with the highest abundance in the $s n-2$ position. $18: 2$ was largely located in position $s n-2$, with approximately $25 \%$ present at $s n-3$ and little (approx. $8 \%$ ) at $s n-1$. $\gamma 18: 3$ was largely present at position $s n-3$, with the lowest level at the $s n-1$ position.

\section{DISCUSSION}

TAG biosynthesis occurs in the endoplasmic reticulum in oilseeds (Stymne \& Stobart, 1987), although some activity has been reported in oil-body preparations (Gurr et al., 1974). In subcellular fractionation studies with the oleaginous yeast Candida curvata, however, it was concluded that PA formation was mainly located in the mitochondrion and that recombining all subcellular fractions (lipid bodies, spheroplasts, mitochondria and soluble supernatant) was necessary to achieve TAGsynthesizing activity (Holdsworth \& Ratledge, 1991). In the present study microsomal membranes contained the highest activity of TAG-synthesizing enzymes. The membranes were capable of the complete assembly of TAG from precursor acyl-CoA and glycerol 3-phosphate substrates at rates comparable to those reported for oilseeds (Stymne \& Stobart, 1985; Griffiths \& Harwood, 1991).

Labelling studies with $\left[{ }^{14} \mathrm{C}\right]$ acetate indicated that fatty acids synthesized de novo were rapidly incorporated into the accumulating oil, with negligible quantities detected in the intermediates of the pathway, namely PA and DAG. The pattern of fatty acids synthesized indicates that $\Delta 9, \Delta 12$ and $\Delta 6$ desaturases were active and that labelling of the acyl moieties of the two phospholipids, PC and PE, occurred initially and with time radioactivity accumulated in TAG. The kinetics of labelling of the two phospholipids and the accumulation of $\left[{ }^{14} \mathrm{C}\right] \gamma 18: 3$ and the concomitant decrease in radioactivity in $\left[{ }^{14} \mathrm{C}\right] 18: 1$ indicate a role for these complex lipids in fatty acid desaturation. In oilseeds PC is the major substrate for $\Delta 12$ and $\Delta 6$ desaturase activity, with the activity of the latter enzyme restricted to linoleoyl groups esterified exclusively to the $s n-2$ position (Griffiths et al., 1988a). In microsomal membrane preparations incubated with $\mathrm{NADH}$ we have also previously observed increases in the mass of $\gamma 18: 3$ in endogenous PE (Stymne et al., 1987). However, studies in vitro, with microsomal membranes under conditions of rapid TAG biosynthesis (i.e. in the presence of acyl$\mathrm{CoA}$ and glycerol 3-phosphate) have indicated that PE is 
not a prime substrate in the production of polyunsaturated fatty acids for other lipids (Stymne \& Stobart, 1987). This was further supported by results of studies in vivo using tissue slices of developing cotyledons in which PC was almost exclusively the only phospholipid labelled with acetate or a range of labelled fatty acid precursors (Griffiths et al., 1988b). In M. circinelloides, PI has been suggested as a major substrate for $\gamma 18: 3$ synthesis based on changes in the endogenous mass of fatty acids in microsomal membrane preparations (Kendrick \& Ratledge, 1992). However, in the present study there was little labelling of PI from acetate under conditions in vivo. Recently, we have shown that $\mathrm{PC}$ is the major substrate for the production of 18:2 and also of $\gamma 18: 3$ in $M$. circinelloides using microsomal membranes supplied with acyl-CoA substrates under desaturating conditions (i.e. in the presence of $\mathrm{NADH}$ ) (Jackson et al., 1998).

The phosphatidic acid phosphohydrolase (PAP) enzyme in $M$. circinelloides appears to be insensitive to changes in $\mathrm{Mg}^{2+}$ concentration, unlike the safflower enzyme (Griffiths et al., 1985). In mammalian tissues, PAP has been suggested to be the rate-limiting step in TAG assembly and is regulated by enzyme translocation between the cytosolic and endomembranes (Hopewell et al., 1985). A similar regulatory mechanism has been proposed for the oilseed enzyme (Ichihara et al., 1990). The purified enzyme from Saccharomyces was also reported to have an absolute requirement for $\mathrm{Mg}^{2+}$ (Hosaka \& Yamashita, 1984). The accumulation of PA in membranes used in the present study suggests that it may also be a rate-limiting step in the production of TAG in M. circinelloides.

Accumulation of PA in the microsomal membranes, especially at the lower $\mathrm{pH}$, allowed investigation of the acyl specificity and selectivity properties of glycerol 3phosphate-acylating enzymes. Palmitoyl-CoA used as a single substrate was almost evenly distributed between position $s n-1$ and $s n-2$ of PA, indicating that the first and second acyltransferases (converting glycerol 3-phosphate to lysophosphatidate and to PA by acylation at the $s n-2$ position) were not specific for unsaturated fatty acids, unlike the oilseed enzyme (Griffiths et al., 1985). The unsaturated acyl-CoA species were also acylated to both positions of PA. Therefore neither GPAAT nor LPAAT showed specificity for certain acyl-CoA substrates, with saturated and unsaturated species being acylated to both positions. In selectivity studies, however, with mixed acyl-CoA being presented to membranes, GPAAT showed a greater selectivity for palmitate whereas LPAAT showed selectivity for unsaturated fatty acids. Studies on the rate of acylation of lysophosphatidic acid by acyl-CoA:1-acylglycerol 3-phosphate acyltransferase (LPAAT) indicated that the activity of this enzyme was particularly high compared with that from sunflower and guinea pig; this may account for the rapid accumulation of PA in $M$. circinelloides membranes. The distribution of fatty acids between the three positions of the glycerol backbone also reflects, to some extent at least, the selectivity properties in vivo of the glycerol-acylating enzymes. The analyses revealed a strong agreement between the distribution of acyl groups in TAG and the selectivity properties of the acylation enzymes. $\gamma 18: 3$ was present at all three positions and was particularly enriched at the $s n-3$ position, perhaps indicating some selectivity for this fatty acid by the diacylglycerol:acylCoA acyltransferase. The ability of microsomal membranes to carry out the complete assembly of TAGs may facilitate future work aimed at understanding the regulation of this process in fungi and help in the future improvement of microbial oil quality for biotechnical applications.

\section{ACKNOWLEDGEMENTS}

We thank the Biotechnology and Biological Sciences Research Council for support. Keith Stobart thanks the Royal Society (UK) for an equipment grant and also Professor R. A. Herbert (Dundee) for the supply of $M$. circinelloides cultures.

\section{REFERENCES}

Bligh, E. G \& Dyer, W. J. (1959). A rapid method of total lipid extraction and purification. Can J Biochem Physiol 37, 911-917.

Brenner, R. R. (1982). Nutritional and hormonal factors influencing desaturation of essential fatty acids. Prog Lipid Res 20, $41-48$.

Burnanova, L., Rezanka, T. \& Jandera, A. (1990). Screening for strains of the genus Mortierella showing elevated production of highly unsaturated fatty acids. Folia Microbiol 35, 578-582.

Certik, M., Sereke Berhan, S. \& Sajbidor, J. (1993). Lipid production and fatty acid composition of selected strains belonging to Mucorales. Acta Biotechnol 13, 193-196.

Christie, W. W. (1982). Lipid Analysis. Oxford: Pergamon Press. Griffiths, G. \& Harwood, J. L. (1991). The regulation of triacylglycerol biosynthesis in cocoa (Theobroma cacao L.). Planta 184, 279-284.

Griffiths, G., Stobart, A. K. \& Stymne, S. (1985). The acylation of $s n$-glycerol 3-phosphate and the metabolism of phosphatidate in microsomal preparations from the developing cotyledons of safflower (Carthamus tinctorius L.) seed. Biochem J 230, 379-388. Griffiths, G., Stymne, S. \& Stobart, A. K. (1988a). Delta-6 and delta-12 desaturase activities and phosphatidic acid formation in microsomal preparations from the developoing cotyledons of common borage (Borago officinalis). Biochem J 252, 641-647.

Griffiths, G., Stymne, S. \& Stobart, A. K. (1988b). The utilisation of fatty-acid substrates in triacylglycerol biosynthesis by tissueslices of developing safflower (Carthamus tinctorius L.) and sunflower (Helianthus annuus L.) cotyledons. Planta 173, 309316.

Griffiths, G., Jones, H. E., Eaton, C. L. \& Stobart, A. K. (1997). Effect of n-6 polyunsaturated fatty acids on growth and lipid composition of neoplastic and non-neoplastic canine prostate epithelial cell cultures. Prostate 31, 29-36.

Gurr, M. J., Blades, J., Appelby, R. S., Smith, C. G., Robinson, M. P. \& Nichols, B. W. (1974). Triglyceride biosynthesis and storage in whole seeds and oil bodies of Crambe abyssinica. Eur $J$ Biochem 43, 281-290.

Harwood, J. L. (1988). Fatty acid metabolism. Annu Rev Plant Physiol Plant Mol Biol 39, 101-138. 
Holdsworth, J. E. \& Ratledge, C. (1991). Triacylglycerol synthesis in oleaginous yeast Candida curvata. Lipids 26, 111-118.

Hopewell, R., Martin-Sanz, P., Martin, A., Saxton, J. \& Brindley, D. N. (1985). Regulation of the translocation of phosphatidate phosphohydrolase between the cytosol and the endoplasmic reticulum. Biochem J 232, 485-491.

Horrobin, D. F. (1990). Omega-6 Essential Fatty Acids: Pathophysiology and Roles in Clinical Medicine. New York: WileyLiss.

Horrobin, D. F. (1994). New Approaches to Cancer Treatment: Unsaturated Lipids and Photodynamic Therapy. London: Churchill Communications International.

Hosaka, K. \& Yamashita, S. (1984). Partial purification and properties of phosphatidate phosphatase in Saccharomyces cerevisiae. Biochim Biophys Acta 796, 102-109.

Ichihara, K., Murota, N. \& Fujii, S. (1990). Intracellular translocation of phosphatidate phosphatase in maturing safflower seeds: a possible mechanism of feedforward control of triacylglycerol synthesis by fatty acids. Biochim Biophys Acta 1043, 227-234.

Jackson, F. M., Fraser, T. C. M., Smith, M. A., Lazarus, C., Stobart, A. K. \& Griffiths, G. (1998). Biosynthesis of C18-polyunsaturated fatty acids in microsomal membrane preparations from the filamentous fungus, Mucor circinelloides. Eur J Biochem 252/3, 513-519.

Johnson, D. R., Knoll, L. J., Levin, D. E. \& Gordon, J. I. (1994). Saccharomyces cerevisiae contains four fatty acid activation (FAA) genes - an assessment of their role in regulating protein $N$ myristolation and cellular lipid metabolism. J Cell Biol 127, 751-762.

Kendrick, A. \& Ratledge, C. (1992). Desaturation of polyunsaturated fatty acids in Mucor circinelloides and the involvement of a novel membrane-bound malic enzyme. Eur $J$ Biochem 209, 667-673.

Meesters, P. A. E. P. \& Eggink, G. (1996). Isolation and characterization of a delta-9 fatty acid desaturase gene from the oleaginous yeast Cryptococcus curvatus CBS-570. Yeast 12, 723-730.

Murcott, T., McNally, T., Allen, S., Fothergill-Gilmore, L. \& Muirhead, H. (1991). Purification, characterization and mutagenesis of highly expressed recombinant yeast pyruvate kinase. Eur J Biochem 198, 513-519.

Nakahara, T., Yokochi, T., Kamisaka, Y. \& Suzuki, O. (1992). Gamma-linolenic acid from the genus Mortierella. In Industrial
Applications of Single-cell Oils, pp. 61-97. Edited by D. J. Kyle \& C. Ratledge. Champaign, IL: American Oil Chemists' Society.

Ratledge, C. (1993). Single-cell oils - have they a biotechnological future? Trends Biotechnol 11, 278-284.

Sancholle, M. \& Lösel, D. (1995). Lipids in fungal biotechnology. In The Mycota, vol. 11, Genetics and Biotechnology, pp. 339-367. Edited by U. Kuck. Berlin: Springer.

Slabas, A. R., Fawcett, T., Griffiths, G. \& Stobart, A. K. (1993). Biochemistry and molecular biology of lipid biosynthesis in plants: potential for genetic manipulation. In Biosynthesis and Manipulation of Plant Products, vol. 3, pp. 104-138. Edited by D. Grierson. Oxford: Blackie Academic Press.

Sprecher, H., Luthria, D. L., Mohammed, B. S. \& Baykousheva, M. (1995). Re-evaluation of the pathways for the biosynthesis of polyunsaturated fatty acids. J Lipid Res 36, 2471-2477.

Stobart, A. K. \& Stymne, S. (1985). The interconversion of diacyglycerol and phosphatidylcholine during triacylglycerol production in microsomal preparations of developing cotyledons of safflower (Carthamus tinctorius L.). Biochem J 232, 217-221.

Stobart, A. K. \& Stymne, S. (1990). Triacylglycerol biosynthesis. Methods Plant Biochem, Lipids, Membr Photobiol 4, 19-46.

Stymne, S. \& Stobart, A. K. (1984). Evidence for the reversibility of the acyl-CoA:lysophosphatidylcholine acyltransferase in microsomal preparations from developing safflower cotyledons and rat liver. Biochem J 223, 305-314.

Stymne, S. \& Stobart, A. K. (1985). Oil synthesis in vitro in microsomal membranes from developing cotyledons of Linum usitatissimum L. Planta 164, 101-104.

Stymne, S. \& Stobart, A. K. (1987). Triacylglycerol biosynthesis. In The Biochemistry of Plants: a Comprehensive Treatise, vol. 9, pp. 175-214. Edited by P. K. Stumpf. New York: Academic Press.

Stymne, S., Griffiths, G. \& Stobart, A. K. (1987). Desaturation of fatty acids on complex lipid substrates. In The Metabolism, Structure and Function of Plant Lipids, pp. 405-415. Edited by P. K. Stumpf, J. B. Mudd \& W. D. Nes. New York: Plenum.

Suzuki, O. (1988). Production of gamma-linolenic acid and its industrialization. In Proceedings of the World Conference on Biotechnology for the Fats and Oils Industry, pp. 110-116. Edited by T. H. Applewhite. Champaign, IL: American Oil Chemists' Society.

Zurier, R. B. (1993). Fatty acids, inflammatiom and immune responses. Prostaglandins Leukot Essent Fatty Acids 48, 57-62.

Received 6 February 1998; revised 30 April 1998; accepted 22 May 1998. 